\title{
The Results of a Roundtable Discussion Involving Young Women in a Rural Community in Enugu State, Nigeria
}

\author{
Marychristiana E. Uzochukwu \\ School of Nursing, College of Health and Human Sciences, North Carolina Agricultural and Technical State University, \\ Greensboro, North Carolina, USA \\ Email: mcuzochu@ncat.edu
}

How to cite this paper: Uzochukwu, M.E. (2018) The Results of a Roundtable Discussion Involving Young Women in a Rural Community in Enugu State, Nigeria. Open Access Library Journal, 5: e4322. https://doi.org/10.4236/oalib.1104322

Received: January 11, 2018

Accepted: February 24, 2018

Published: February 27, 2018

Copyright $\odot 2018$ by author and Open Access Library Inc.

This work is licensed under the Creative Commons Attribution International License (CC BY 4.0).

http://creativecommons.org/licenses/by/4.0/

(c) () Open Access

\begin{abstract}
Introduction: Eleven young women ages 18 to 20 years living in a rural community in Enugu State, Nigeria participated in a roundtable discussion to identify major health concerns facing them in their rural community. The main purpose of the discussion was to initiate empowerment process among these young women and to use data collected to seek ways to improve the health status of young women in this rural community. Method: These women were recruited by word of mouth and consented to participate in the discussion. The roundtable format provided a friendly environment, which permitted each of the young women to speak in acknowledgement of concerns raised by others or to add their own concerns. Collectively, these women identified a litany of concerns and challenges which they believe pose a threat to their health in the rural community. Health Concerns/Issues Identified: Their priority concerns were poor sanitation-leading to poor personal hygiene, open defecation-exposing them to infectious agents, contaminated drinking water, early marriages usually to older men-to provide financial support to the family, early sexual activities with older men-to get money to take care of personal needs, and lack of income generating domestic skills-to take care of personal hygiene needs, which they ranked as the number one priority. Conclusion: Participation in the roundtable discussion created a bond among these women. A non-profit private foundation has agreed to sponsor demonstrations of domestic skills that can generate income for these young women, but their concerns warrant public health attention.
\end{abstract}

\section{Subject Areas}

Public Health 


\section{Keywords}

Health Status, Poor Sanitation, Poor Personal Hygiene, Open Defecation, Infectious Agents, Contaminated Drinking Water, Early Marriages, Early Sexual Activities, Income-Generating Domestic Skills

\section{Introduction}

Poverty is a global health issue affecting many areas in both developed and developing countries. Poverty presents issues that challenge healthy living and increase risks for developing preventable diseases. People residing in rural areas of developing countries, particularly women are disproportionately exposed to challenges that threaten their health status. Evidence of poverty across the globe abounds, which contributed to inspiring world leaders to take collective action in 2000, declaration to: eradication of extreme poverty, hunger, disease, illiteracy, environmental degradation, and discrimination against women [1]. All 191 United Nations member countries agreed to attempt to achieve the eight goals known as the Millennium Development Goals [MDGs], derived from the declaration by world leaders in September 2000 by the year 2015 [1].

Findings from several studies support that poverty is higher in rural areas when compared to urban areas of the world [2] [3] [4]. Lack of schooling and lack of empowerment of women were on top of the contributing factors to poverty among women in Sub-Saharan African countries, including Nigeria [2].

Chimezie [5], in a recent publication provided wealthy information about living conditions in rural Nigeria communities including little or no income generating opportunities, lack of water, lack of power supply, absence of good health facilities, poor sanitation, bad roads, and poor housing. All the above mentioned conditions increase risks to developing preventable diseases which contribute to poor health status among populations in rural areas including those of young women. Egbe [6], in a recent study quoted features of rural areas including poverty, deprivation, degradation and went on to indicate that basic infrastructures are missing in most rural communities in Nigeria and are inadequate where they exist in. The above information underscores the need for better living conditions for better health.

Inspired by the desire to contribute in building healthier communities by improving living conditions of people, the roundtable discussion was conducted to get more insights from a predetermined group, women. It has been noted that women are affected disproportionately by poor living conditions in rural areas [7]. This article presents the results of the roundtable discussion involving young women in a rural community in Enugu State, Nigeria, in West Africa. Eleven young women ages 18 - 20 years residing in a rural community in Enugu State, Nigeria responded to a word of mouth invitation and participated in a roundtable discussion to identify major health concerns facing them in their rural com- 
munity. The purpose of using a roundtable approach in this discussion was to create a bond and initiate an empowerment process among these young women. The intention is to use data collected to seek ways to improve the health status of young women in this rural community.

\section{Method}

This study took place in August 2014. Lolo of the town (the Wife of the traditional Ruler, considered as the mother figure of all people in the town) granted ethical clearance to conduct this study. Purposive and snowballing sampling was used to isolate my sample since the group of participants was predetermined-young women between the ages of 18 - 30. Trochim and Donnelly [8] support the use of purposive sampling if a study group is predetermined. Snowballing sampling where those recruited already referred and helped recruit others was suitable for this study.

I intended to recruit about $10-20$ participants. I believed that 10 participants, should be able to provide valuable information on issues facing young women in their community. The justification for planning not to exceed 20 participants was simply due to space/accommodation. The setting had allowance for 20 participants, not more. I did not want an overcrowded situation, which could be uncomfortable for participants.

Participation in this study was open to young women residing in this rural community between the ages of 18 to 35 years old. As indicated by Lolo of the town, people do not need parental consent at 18 years and when a woman is above 35 years, she is no longer considered a young woman. I excluded from this study those who were less than 18 years and above 35 years. The young women were recruited by word of mouth after permission was granted by the Lolo of the town. Participants were informed of the purpose of the discussion and the intended use of the data. They were informed that they could stop participating any time if so desired. All the participants consented to participation and provided permission for their pictures to be taken and for the discussions to be recorded to make sure that the information they conveyed were accurately captured. All the participants consented to using their pictures in articles and in developing grant proposals in effort to seek sustainable help for them. The participants were asked to identify what they considered issues facing them in their community. The roundtable format permitted each person to speak, either to identify an issues or to support the issues that others had identified. Identification of issues ceased when redundancy was reached.

\section{Basic Demographics of the Participants}

Eleven women participated in this study $(N=11)$. One was 20 years, two were 19 years, and eight were 18 years. One participant was married with a child and the rest were single and had no children. Four completed high school (called secondary school) and seven completed Elementary school. None of the partici- 
pants was earning any income of their own.

\section{Health Concerns/Issues Identified}

The young women identified a litany of issues which included the following:

Lack of civilization/lack of discipline; Bad influences, usually friends/poor performance at school due to lack of teachers and other obligations expected from parents (many chores to do after school); No electricity, therefore no television, no access to useful information; Issues with neatness, poor sanitary conditions; Lack of latrines/poor personal hygiene; Defecation in bushes which contaminates up drinking water after rain serious need for boreholes; Issues with boys: smoking of weeds and other things, make them violence, serious madness, beating up girls when they resisted their advances, rapes, fighting, killing, even fighting and hurting family members (one mentioned a boy fighting his grandmother); Early sexual activities just to get money, pregnancy, which could lead to abortion and even death; Arranged early marriage, most of the time to a much older man just for the family to get financial help; No paying jobs; Lack of profitable domestic skills (making buns, puff-puff, chin-chin); and Poor road conditions, making transportation very difficult.

Participants were asked to rank the issues that they identified in order of priority, and unanimously, they chose acquiring profitable domestic skills as number one priority. Domestic skills as they indicated included baking/quality food preparation, sewing, hair dressing (skills that have daily application). When asked the reason for ranking acquiring money-generating domestic skills as number one, they indicated that profitable domestic skills would generate money which they could use to address some of their personal hygiene issues, thereby reducing their risk of getting into undesired sexual practices just to get money for personal hygiene (Figure 1).

\section{Discussion of Issues}

These 11 young women responded to a word of mouth invitation and participated in the roundtable discussion that was mainly intended to identify issues that young women face in their community. They were the voices of a rural community in Enugu State, Nigeria, in West Africa.
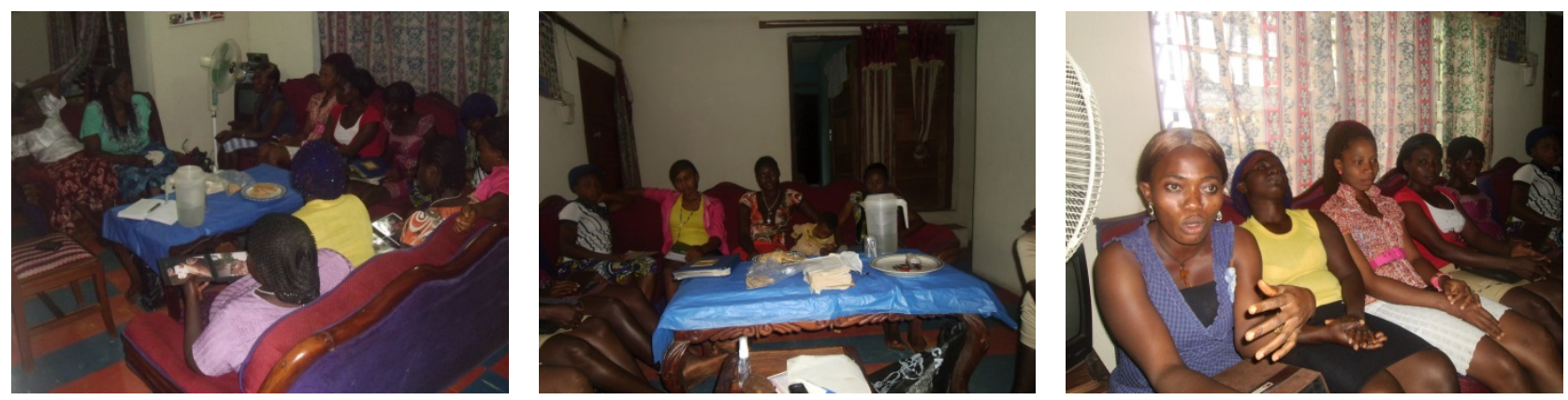

Figure 1. Snapshots of roundtable participants. 
Issues identified by these Young Women Roundtable Discussion Participants:

\subsection{Lack of Civilization/Lack of Discipline}

These young women indicated that by residing in rural community, they lack civilization/discipline. They all desire to see the "light" as they put it, which means life beyond their rural community, which they believe would present them with more opportunities to grow, capable of taking charge of their lives, and contributing positively to the overall growth of their community. They yearn for what they called reliable role models/mentors to help them along the way.

\subsection{Bad Influences, Usually Friends/Poor Performance at School Due to Lack of Teachers and Other Obligations Expected from Parents (Many Chores to Do after School)}

These young women focused on school when they discussed bad influences. Per their discussions, due to adverse conditions in Nigeria, particularly in rural areas, there are scarcity of teachers and some available ones tend to present non-caring attitude, which affects the way some students behave at schools. Some of them have succumbed to peer pressure and neglected their school work. Some just go through the motion of going to school, without paying attention to learning which leads to them failing their courses and having to retake them. Most of the time, their parents are unable to afford the money for school fees and other school related expenses, leaving them with the only option, which is dropping out of school. For some, their poor performance at school is simply because they have a lot of chores to do after school, leaving them with little or no time to address their school work.

\subsection{No Electricity, Therefore No Television, No Access to Useful Information}

In discussing lack of electricity, the participants connected it to lack of civilization, which grossly limits opportunities for them. They talked about the rural electrification project that brought electricity to town only to create the "now you see it; now you don't phenomenon". They discussed how the light never comes on any more, when compared to the initial implementation of the rural electrification project. Usually, people would gather at their neighbors' places who have television to watch television and possibly obtain crucial information/news on events.

\subsection{Issues with Neatness, Poor Sanitary Conditions}

These young women discussed poor sanitary conditions at their homes and the environments, which results to some of their homes not being as neat as they would like to be some times. The talked about dirty dishes and cooking utensils piling up at homes due to scanty water, coupled with no soap/dish soap to appropriately wash the dishes. 


\subsection{Lack of Latrines/Poor Personal Hygiene}

They all complained about lack of latrines and the consequential poor personal hygiene.

Per their discussions, women need very good personal hygiene which means, privacy when using the bathroom to permit their cleaning up appropriately, particularly during their menstrual period.

\subsection{Defecation in Bushes Which Contaminates up Drinking Water after Rain/Serious Need for Boreholes}

Defecation in bushes directly relates to lack of latrines. In discussing this, they focused on how feces contaminate drinking water and utility water alike with the consequential diarrhea and other water/food borne diseases. They yearn for functional boreholes. As they noted, they have seen where boreholes are present, but sometimes, no water.

\subsection{Issues with Boys}

These young women discussed many issues that young women face with boys (young men) in their community. Per their discussion, many young men smoke weeds and "other things" as they put it, which make them high and irresponsible. Sometimes they get violent and beat up girls (young women) and members of their family. They would often chase young women to have sex, and when they resist, the young men would claim that they indeed had sex with the women and spread the word to other men; rape them; beat them up; and even some have killed women in this process, which scares them. As mentioned by one participants, one young man, they all know had a serious fight with the grandmother, because the grandmother strongly disapproves his behaviors towards women.

\subsection{Early Sexual Activities Just to Get Money, Pregnancy, Which Leads to Abortion and Even Death}

Participants discussed how desperation for money just to take care of their personal hygiene makes women have sex usually with older men (because they have money) at early age. Sometimes, they get pregnant and some would have abortions, which have resulted in deaths of young women like them due to use of quasi doctors, with no medical credentials.

\subsection{Arranged Early Marriage, Most of the Time to a Much Older Man Just for the Family to Get Help}

Young women even younger than them have gotten married due to arrangement by the parents or grandparents. Usually, this kind of arrangement involves wealthy older men, with the intention for the men to help out the brides' family financially.

\subsection{No Paying Jobs}

They all yearn for paying jobs; not just chores in their respective families. One of 
the factors that they indicated as an interference with their concentration in their school work education is doing chores at home. They know that they need to do that. They would all like to have paying jobs, which are not available in this rural community.

\subsection{Lack of Profitable Domestic Skills Making Buns, Poff-Poff, Chin-Chin}

They lack profitable domestic skills as discussed earlier as a way to generate income for them in order to help them take care of their personal needs such as toiletries, clothes, and under garments.

\subsection{Poor Road Conditions, Making Transportation Very Difficult}

Particularly during the rainy season, the road conditions are poor in the rural communities. Per their discussions, poor road conditions disturbs public transportation in and out of the community, which makes it hard for them to get out even to a nearby market to buy food materials and others.

\section{Summary}

These issues identified by the young women who participated in this roundtable discussion are very real public health issues and should be of a great concern to the local, state, national and global society. Many issues affecting public health in African countries including poor sanitation, poor personal hygiene, contaminated drinking water sources, have been topics of many discussions for years [9] [10] [11]. The participants are faced with these issues daily. These young women ranked acquiring money-generating domestic skills as the number one priority in order to offset other personal issues that require money. The personal issues requiring money to address centered on neatness, sanitary condition and personal hygiene, including but not limited to, having minimum underwear, minimum sanitary towels during menstrual periods, and minimum toiletries.

Their discussions revealed that, it does not require elaborate preparations and equipment to start the home-based business of preparing the fried/baked items described above. As one participant indicated, they can use what they already use in food preparation at their respective homes such as pot. Frying pans, serrated big spoons, fire woods, basins. Essentially, the items that would need to be purchased anew would be the ingredients to prepare the desired food items and possibly special pans/showcases to display the finished products. In a rural community, word of mouth is great in spreading the news about what is new, and as they indicated, the aroma of the food being prepared would attract and direct customers to the right place. The participants plan to prepare and sell their items at their respective homes at least during the initial stages until enough fund is generated to warrant expansion, meaning obtaining a stable place in the area markets.

Efforts to address the number one-ranked issue started at the conclusion of 
the roundtable discussion. Participants provided their contact information. Arrangements to train these young women in domestic skills such as making chin-chin (chin-chin is made using similar ingredients in making cookies, but it is deep-fried); making puff-puff (puff-puff is a yeast bread that is molded in little balls and is deep-fried); and making buns (buns is made using similar ingredients in making cake, with batter thicker to permit molding in small balls and is deep-fried) are underway.

Uzo Foundation Inc., a private nonprofit foundation has agreed to sponsor the domestic skills training by December of 2017. The author plans to develop a grant proposal to solicit financial assistance from other non-profit foundations/organizations to enable these young women to start generating income after acquiring the very much needed domestic skills. Generating their own income means a great deal to these women because that would help them take care of their personal hygiene needs, keep them engaged and productive in the community.

\section{Conclusion}

Participation in this roundtable discussion created a bond among these young women with a strong sense of empowerment. They represent the voices of young women in their community. They are open to ideas and yearn for opportunity to acquire domestic skills which they can use as source of income.

\section{References}

[1] World Health Organization (2018) Millennium Development Goals. http://www.who.int/topics/millennium_development_goals/about/en/

[2] Batana, Y.M. (2013) Multidimensional Measurement of Poverty among Women in Sub-Saharan Africa. Social Indicators Research, 112, 337-362.

https://link.springer.com/article/10.1007/s11205-013-0251-9 https://doi.org/10.1007/s11205-013-0251-9

[3] Booysen, F., Von Maltitz, M., Van Der Berg, S., Burger, R. amd Du Rand, G. (2008) Using an Asset Index to Assess Trends in Poverty in Seven Sub-Saharan African Countries. World Development, 36, 1113-1130.

https://www.sciencedirect.com/science/article/pii/S0305750X08000466?via\%3Dihub https://doi.org/10.1016/j.worlddev.2007.10.008

[4] Chant, S. (2006) Re-Thinking the "Feminization of Poverty" in Relation to Aggregate Gender Indices. Journal of Human Development, 7, 2. http://personal.lse.ac.uk/chant/chantpdfs/Chant_JHD_PDF.pdf https://doi.org/10.1080/14649880600768538

[5] Chimezie, R.O. (2015) Primary Healthcare in Nigeria: Overview, Challenges, and Prospects. Outskirts Press, Parker, Colorado.

[6] Egbe, E.J. (2014) Rural and Community Development in Nigeria: An Assessment. Arabian Journal of Business and Management Review (Nigeria Chapter), 2, 17-30. http://www.arabianjbmr.com/pdfs/NG_VOL_2_2/3.pdf

[7] Rural Women and Millennium Development Goals (n.d.). http://www.un.org/womenwatch/feature/ruralwomen/documents/En-Rural-Wome n-MDGs-web.pdf 
[8] Trochim, W.M.K. and Donnelly, J.P. (2008) The Research Methods: Knowledge Base. Cengage Learning, Mason.

[9] World Health Organization (2006) Meeting the MDG Drinking Water and Sanitation Target: The Urban and Rural Challenge of the Decade. http://www.who.int/water_sanitation_health/monitoring/jmpfinal.pdf

[10] Awuah, E., Nyarko, K.B., Owusu, P.A. and Osei-Bonsu, K. (2009) Small Town Water Quality. Desalination, 248, 453-459. https://doi.org/10.1016/j.desal.2008.05.087

[11] Lewis, L. (2009) Rural and Urban Issues in Africa.

http://thewaterproject.org/pdf/rural-and-urban-water-issues-africa.pdf 